\title{
APPLICATION OF A SOFTWARE PROGRAMME LANGUAGE CALLED PYTHON IN DETERMINING THE LOADS AND LOAD DISTRIBUTION IN THE DECKS OF A LONG SPAN REINFORCED BRIDGE DECK
}

\author{
IfeOlorun Olofin ${ }^{1}$, Ronggui Liu ${ }^{2}$ \\ ${ }^{I}$ PhD student, Civil Engineering, Jiangsu University, Jiangsu, China \\ ${ }^{2}$ Professor, Civil Engineering, Jiangsu University, Jiangsu, China
}

\begin{abstract}
This research was to create software that can analyze, design and determine the cost of a beam/ deck for a simple supported bridge, the name of the software is Ivy. The method employed for the analysis is a grillage method, using finite element (beam element) and comparing the results with a manual approach (moment distribution and influence line). A $15 \mathrm{~m}$ span was considered with a width of $7.5 \mathrm{~m}$, using a grillage distance of $1.5 \mathrm{~m}$, a knife edge load of $120 \mathrm{KN}$ and a uniformly distributed load of $30 \mathrm{KN} / \mathrm{m}$. The BS5400 and BS 8110 were used for the analysis and design. The result shows that values for the maximum bending moment locating the knife edge at $3 \mathrm{~m}$ from the support is Mmax $=412 \mathrm{KNm}$ (manual approach), Mmax= 506.25KNm (Ivy) to give a percentage difference of $18.6 \%$, at $6 \mathrm{~m}$, Mmax $=653 \mathrm{KNm}$ (manual approach), and Mmax $=566.25 \mathrm{KNm}$ with a percentage difference of $-15.3 \%$, at mid span $7.5 \mathrm{~m}$, it is Mmax=789KNm (manual approach), Mmax= 768.75KNm(ivy) indicating a percentage difference of $-2.63 \%$. Similarly, the shear force at support locating the knife edge load at $3 \mathrm{~m}$ is Vmax= $24.81 \mathrm{KN}$ (manual approach), and Vmax $=33.75 \mathrm{KN}$ (ivy) to give a percentage difference of $26.4 \%$, at $6 \mathrm{~m}$, Vmax $=57.58 \mathrm{KN}$ (manual approach), and Vmax $=67.50 \mathrm{KN}$ (ivy) to give a percentage difference of $14.6 \%$ while at mid span $7.5 \mathrm{~m}, \mathrm{Vmax}=38.98 \mathrm{KN}(\mathrm{manual}$ approach), and Vmax $=67.50 \mathrm{KN}$ (ivy) to give a percentage difference of $42.2 \%$. The main reinforcement area of steel locating the knife edge load at $3 \mathrm{~m}$ is As $=5419 \mathrm{~mm}^{2}$ (manual approach), and As $=5271.72 \mathrm{~mm}^{2}$ (ivy) with a percentage difference of $-2.7 \%$; at $6 \mathrm{~m}, \mathrm{As}=6145 \mathrm{~mm}^{2}$ (manual approach), and $\mathrm{As}=5910.52 \mathrm{~mm}^{2}$ (ivy) with a percentage difference of $-3.9 \%$, while at mid span $7.5 \mathrm{~m}, \mathrm{As}=8617 \mathrm{~mm}^{2}$ (manual approach), and As $=8088.6 \mathrm{~mm}^{2}$ (ivy), giving a percentage difference of $-6.5 \%$
\end{abstract}

Keywords: Simply supported long span bridge/deck, Python, Finite element (beam element)

\section{BACKGROUND INFORMATION}

Bridge engineering has been one of the most crucial parts of civil engineering design projects. Engineers are faced with daunting task in designing and erecting this structure. One of the major problems of bridge design are its loads and load distribution. There are lots of methods used in the analysis and design of a bridge, but this research is based on the development of finite element model of a long span bridge decks as a grillage using a software programme language called Python. A long span bridge can be defined as a bridge with great distances which are held up by at least two support set to the ground. Bridges ranges in length from a few metres to kilometers.

"Python is a dynamic object-oriented programming language that can be used for many kind of software development. It offers strong support for integration with other languages and tools comes with extensive standard libraries and can be learned in a few days. Many python programmers report substantial productivity gains and feel the language encourage the development of higher quality, more maintainable code" [17].
The main aim of this paper is to present the results of the development of a software for the analysis and design of a long span reinforced concrete highway bridge based on BS5400(1990) and BS8110(1997), and its application to determine the loads and load distribution in such structures.

\section{OBJECTIVES}

The specific objectives are

- $\quad$ to model the deck/ beam system using finite element

- $\quad$ to develop a software for the design of the members.

- $\quad$ to test the model and design and compare it with manual design.

\section{METHODS}

An algorithm for the development of a mesh was created using the finite element method for the bridge element .The computer analysis was carried out using the input data which describe fully the idealized structure and its loading, and produces output consisting of tabulated nodal displacements and element stresses. Figure 1 summaries the basic requirement of the computer program necessary for the complete solution of a program by finite element method. 


\subsection{Analysis and Design of a Bridge Deck Algorithm and Description}

The detailed of the design and analysis procedures adopted for the study are illustrated in Figures 1 and 2
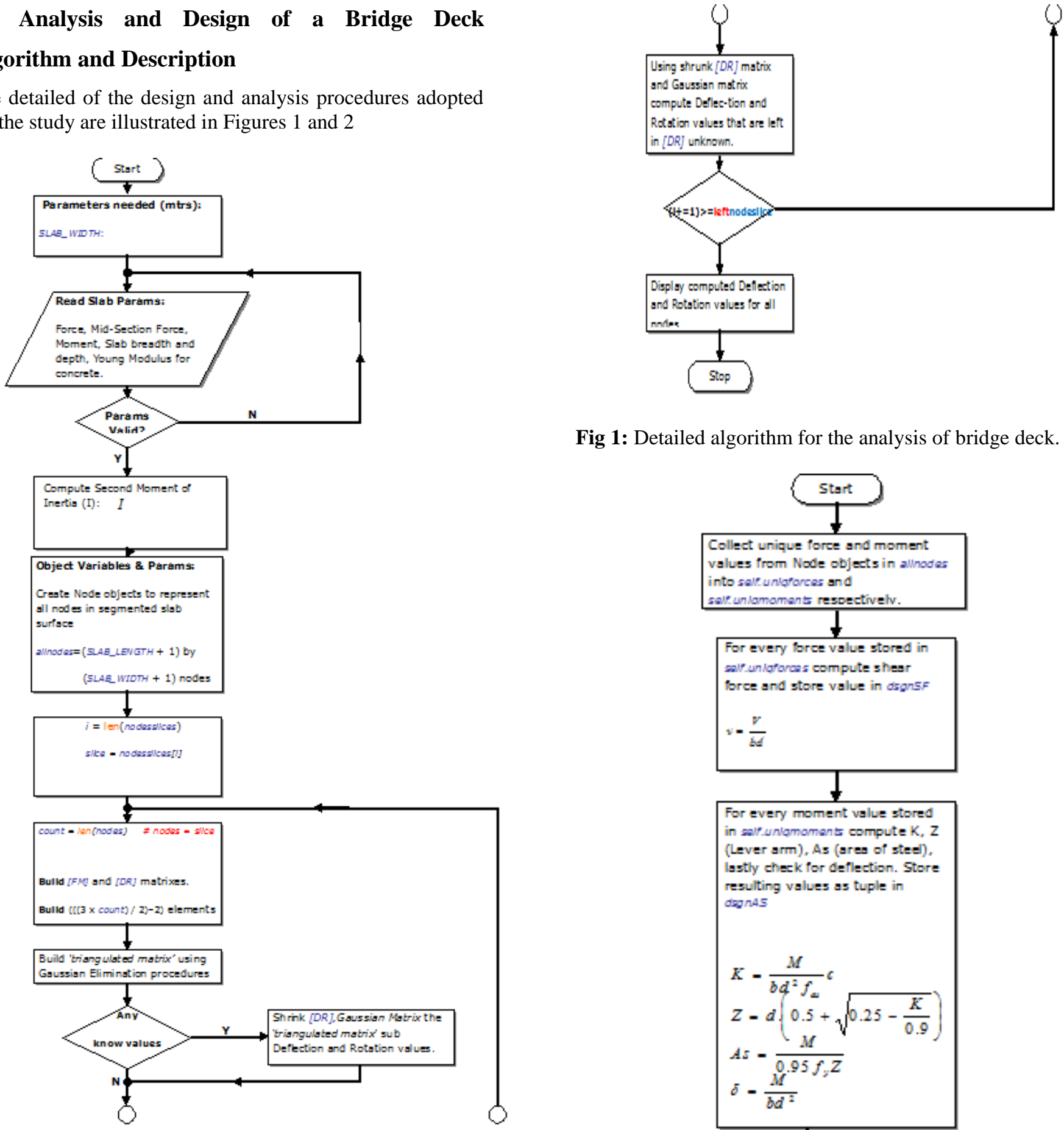

Fig 1: Detailed algorithm for the analysis of bridge deck.

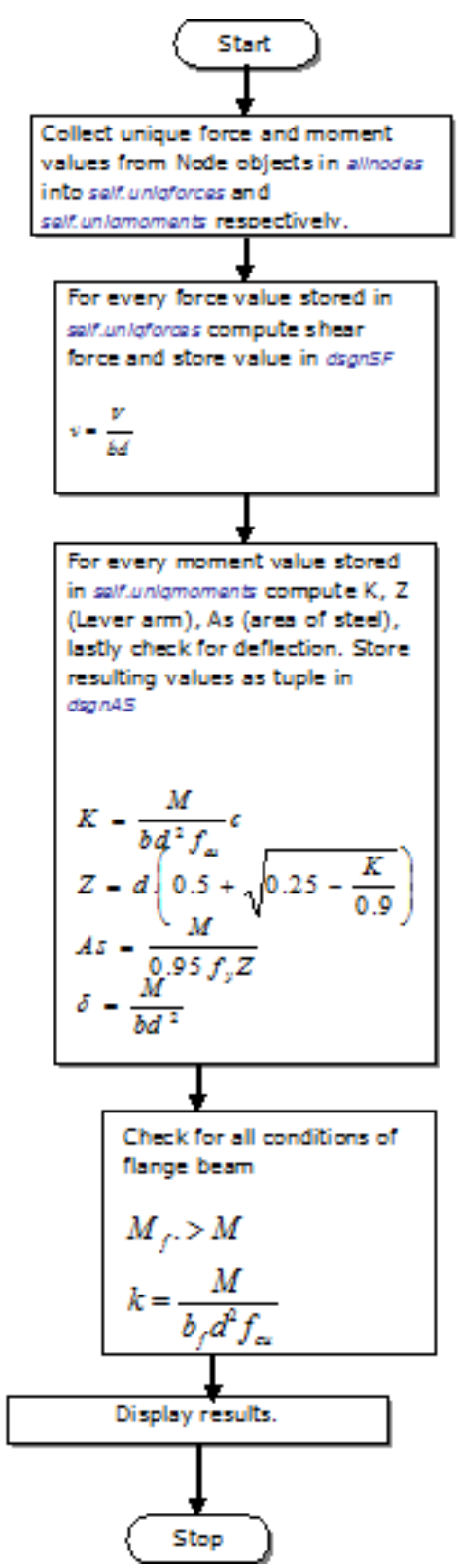

Fig 2: Detailed algorithm for the design of the bridge deck 
The structural analysis and design of the bridge consist of a reinforced concrete deck of $15 \mathrm{~m}$ long simply supported, 7.5 $\mathrm{m}$ wide and a meter deep. The layout of grillage consists of 5 longitudinal members, 10 transverse members and 66 numbers of nodes using a grillage length of $1.5 \mathrm{~m}$.

The loading consideration adopted is illustrated in Figure 3.

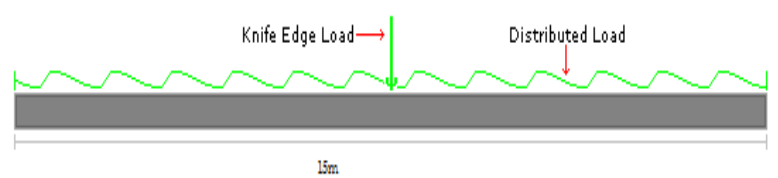

Fig 3: Adopted Loading Consideration

A uniformly distributed load of $30 \mathrm{kN} / \mathrm{m} 2$ was based on the British Standard No 5400,part 2: 1990 (for lengths up to $30 \mathrm{~m})$. A knife edge load of $120 \mathrm{kN}$ was placed at critical points perpendicular to the notional lane. (HA Loading). The element of the deck consisted of a breadth of $1500 \mathrm{~mm}$, depth of $900 \mathrm{~mm}$, slab depth of $100 \mathrm{~mm}$ and a web thickness of $300 \mathrm{~mm}$. An overall height of a meter was employed in the analysis and design of the bridge deck. This is illustrated in Figure 4.

The design criteria adopted included the use of BS 5400[3] and BS 8110[4], all calculations were executed using the Limit State method. The design criteria include the concrete strength of $25 \mathrm{~N} / \mathrm{mm}^{2}$ and young modulus of concrete as 25 $\mathrm{kN} / \mathrm{mm}^{2}$. The high yield value of $460 \mathrm{~N} / \mathrm{mm}^{2}$ based on BS 4449[2]. The reinforcement is considered to be the same order of magnitude in the longitudinal and transverse direction.

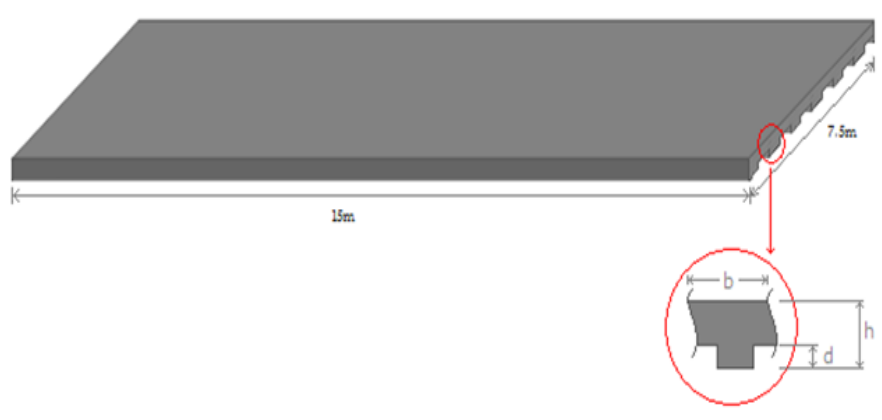

Fig 4: The Element of the Deck

\subsection{Analysis and Design of a Bridge Deck Using}

\section{Manual Approach.}

The structural analysis and design of the bridge consisted of 7 numbers of precast reinforced concrete beams with dimensions 300 x 900 at $1500 \mathrm{~mm}$ center to center. The deck consisted of precast slabs with dimensions $100 \mathrm{~mm}$ over the precast beams to serve as formwork for the $140 \mathrm{~mm}$ deep cast in situ concrete slab on top. The load and forces considered include dead loads and imposed live loads of 30 $\mathrm{kN} / \mathrm{m}^{2}$ which were employed in the analysis. The design criteria and material considered were the same as the one employed for bridge Beam/Deck software.

\subsection{Programming for the Software and Testing the Developed Software}

The Programming for the software adopted was the Python Programme. In its simplest form, a Python programme is just a text file containing Python statements. For example, the following file, named script1.py, is one of the simplest Python scripts, but it passes for an official Python program:

print 'hello world'

print $2 * * 100$

The file contains two python print statement, which simply print a string (the text in quote) and a numeric expression result ( 2 to the power 100) to he output stream.

A file statement of any text editor can be created but the python program files are given names that end in ".py". After the statements are typed into a test file in one way or another, python will execute the file; simply, this means it runs all the statements in the file from top to bottom, one after another. If the program goes well, the result of the two print statement shows up in the computer-by default, usually on the same window the program is run. Consider the following:

hello world

1267650600228229401496703205376

For example, here is how this script ran from a DOS command line on a Window's laptop, making sure it did not have any silly typos:

\section{D:Itemp>python script1.py \\ hello world \\ 1267650600228229401496703205376}

A python script has just been run which printed a string and a number which would capture the basics of the program execution.

The results obtained for the analyses and design of a bridge deck using the ivy bridge was compared with ones undertaken manually. HA loading was considered for the testing.

\section{RESULTS AND DISCUSSION}

This section gives the complete summary of all the findings from the study. The results are discussed with the comparison of established results obtained for the test bridge deck analysis and design. Critical points are taken into consideration in the comparison.

The data for the structure is a uniformly distributed load of $30 \mathrm{kN} / \mathrm{m}^{2}$ and a live edge load of $120 \mathrm{kN} / \mathrm{m}^{2}$ over a width of $7.5 \mathrm{~m}$, length of $15 \mathrm{~m}$ and a meter deep with a grillage of $1.5 \mathrm{~m}$ length as illustrated in fig 6 . 
Table 3: Summary of main reinforcement of steel

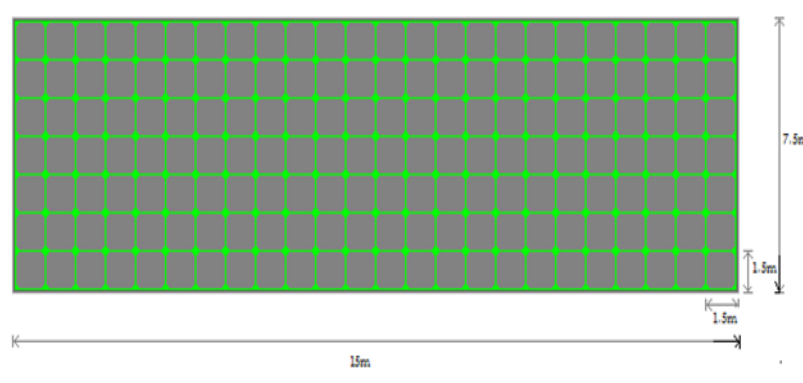

Fig 6: The Data for the Structure

The percentage differences of each value are obtained by the difference between the manual results and CADBBDD result dividing it by CADBBDD result and multiplying by a 100.

The summary of results for the bending moments for the interior beam is illustrated in Table 1 .

Table 1: Maximum Bending Moment Values

\begin{tabular}{|l|l|l|l|}
\hline $\begin{array}{l}\text { Location } \\
\text { of Knife } \\
\text { edge } \\
\text { load (m) }\end{array}$ & $\begin{array}{l}\mathrm{M}_{\max }(\text { Manual } \\
\text { Results) } \\
(\mathrm{KNm})\end{array}$ & $\begin{array}{l}\mathrm{M}_{\max }(\mathrm{CADBBDD}) \\
(\mathrm{KNm})\end{array}$ & $\begin{array}{l}\text { Percentage } \\
\text { Difference } \\
(\%)\end{array}$ \\
\hline 3 & 412 & 405 & -1.7 \\
\hline 6 & 653 & 607.5 & -7.4 \\
\hline 7.5 & 789 & 712.5 & -10.7 \\
\hline
\end{tabular}

The table shows the maximum bending moment's value of a beam, from the deck in questions, values obtained using the manual design are much higher than that of CADBBDD. Similarly, the summary of results for the shear force values for the beam is given in Table 2 .

Tables 2: Shear force values for the beam at the support

\begin{tabular}{|l|l|l|l|}
\hline $\begin{array}{l}\text { Location } \\
\text { of knife } \\
\text { edge load } \\
(\mathrm{m})\end{array}$ & $\begin{array}{l}\text { Forces } \\
(\text { manual }) \\
(\mathrm{KN})\end{array}$ & $\begin{array}{l}\text { Forces(CADBBDD) } \\
(\mathrm{KN})\end{array}$ & $\begin{array}{l}\text { Percentage } \\
\text { difference } \\
(\%)\end{array}$ \\
\hline 3 & 24.81 & 33.75 & 26.4 \\
\hline 6 & 57.58 & 67.50 & 14.6 \\
\hline 7.5 & 38.98 & 67.50 & 42.2 \\
\hline
\end{tabular}

From the results in the table, the shear force values obtained using the manual method is much lower than that of ivy, thereby giving an increase in the percentage difference. The application of the knife edge load gives rise to the values at each of the location points and, of course, a large difference between the values of the two different methods. A percentage increase was established in the shear value computation.

The ultimate bending moment for both loadings are taken into consideration, the areas of both reinforcements are illustrated in Table 3. A percentage decrease was obtained from the results obtained

\begin{tabular}{|l|l|l|l|}
\hline location & $\begin{array}{l}\text { Manual } \\
\text { Method } \\
\text { As }\left(\mathrm{mm}^{2}\right)\end{array}$ & $\begin{array}{l}\text { CADBBDD } \\
\text { As }\left(\mathrm{mm}^{2}\right)\end{array}$ & $\begin{array}{l}\text { Percentage } \\
\text { difference } \\
(\%)\end{array}$ \\
\hline 3 & 5419 & 5092.92 & -4.7 \\
\hline 6 & 6145 & 5910.52 & -3.9 \\
\hline 7.5 & 8617 & 8088.6 & -6.5 \\
\hline
\end{tabular}

The format of the developed software is illustrated in Figure 7. This software for the analysis and design of a reinforced concrete highway bridge deck/beam was developed based on BS 5400[3] and BS 8110[4]. The grillage method of analysis was adopted and the software was written in "python" programming language as explained earlier.

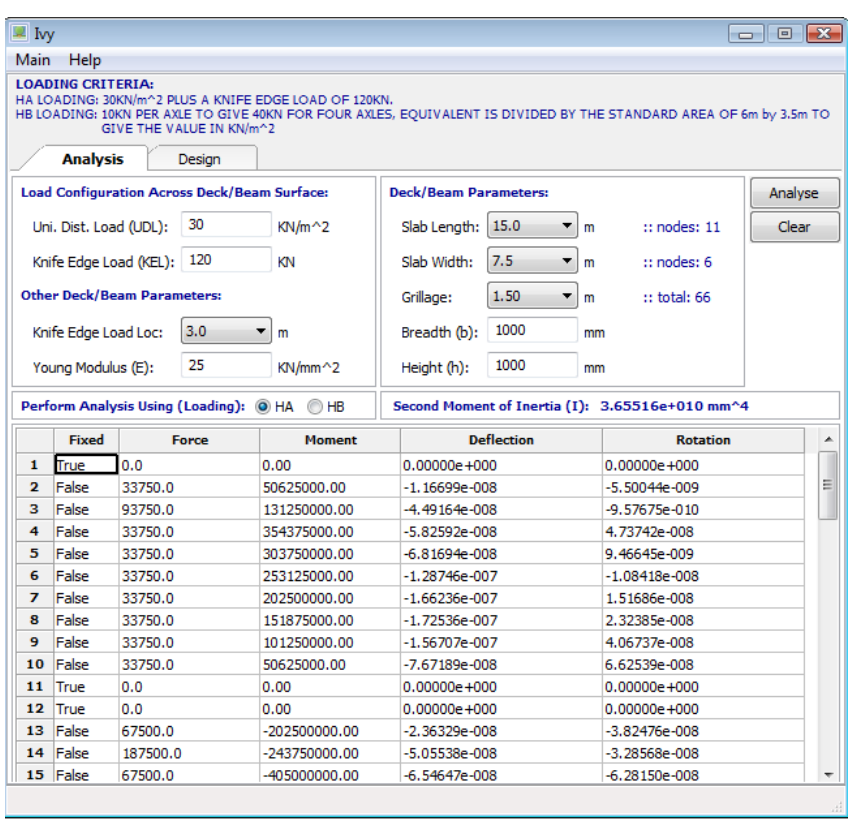

Fig 7: The Software Format

\section{CONCLUSION}

The software was tested for the analysis and design of a typical bridge deck/ beam and results were compared with those from manual method of analysis and design. The results indicate that the developed software provides

i) An easier means of analysis compared to the manual approach which is tedious;

ii) A cheaper cost of materials;

iii) A user-friendly method of analysis, and

iv) An easy-to-learn language.

\section{ACKNOWLEDGEMENTS}

A word of thanks to my supervisor, family and friends for their selfless help and support

\section{REFERENCES}

[1]. Bangash, M.Y.H, Prototype bridge structures: analysis and design, $[\mathrm{M}]$ Thomas Telford, London, Great Britain. (1999) 
[2]. British Standard 4449 Specification for carbon steel bars for reinforcement of concrete. [S] British Standards Institution, London, (1997).

[3]. British Standard 5400-5: Steel, concrete and composite bridges. Code of practice for design of composite bridges. [S] British Standards Institution, London, (2005)

[4]. British Standard 8110-1: Structural use of concrete. Code of practice for design and construction, [S] British Standards Institution, London, (1997)

[5]. Handbook on Unified Code of Structural Concrete (CP110); Cement \& Concrete Association, London, (1972)

[6]. Jackson P Giord and Partners. Design of Reinforced Concrete Bridge: [J] Institution of Civil Engineering (ICE), Manual of Bridge Engineering, Second Edition, Thomas Telford, London, Great Britain, (2008), Pages 185-194

[7]. Martin L.H, Croxton P.C and Purkiss J.A, Concrete Design to BS8110. [M]First Edition London, Great Britain,(1989)

[8]. Morrell,P.J.B, Design of Reinforced Concrete Element, [M]BSP Professional Books, London, Great Britain,(1989)

[9]. Mosely W.H, Bungey J.H and Hulse R, Reinforced Concrete Design,[M] Sixth Edition Macmillan Press Ltd, London, Great Britain, (2007)

[10]. Nilson A.H and Winter G, Design of Concrete Structures, [M] Fourteenth Edition, McGraw Hill, Inc USA,(2009)

[11]. O'Brien E.J , Keogh D.L and Alan J O'Connor, Bridge Deck Analysis, [M]Second Edition ,CRC, Press(2014)

[12]. Rockey K.C, Evans H.R, Griffiths D.W and Nether cot D.A, The finite element method, [M], Second Edition, Crosby Lockwood staples, London, Great Britain.(1991)

[13]. Rowe, R.E, Concrete Bridge Design, [M] Applied Science Publisher Ltd, Ripple Road, Barking,Essex, Great Britain(1962)

[14]. Ryall M.J, Loads and loading distribution,[J] Institution of Civil Engineers (ICE) : Manual of Bridge Engineering, Second Edition, Thomas Telford, London, Great Britain,(2008)

[15]. Tonias D.E , Bridge Engineering,[M] McGraw Hill, Inc, USA(2002)

[16]. World Book, (2013), World book Publishing, Inc, Chicago

[17]. Python programming language, official website. [EB/OL]. [2012-01-14]www.python.org/, copyright 20012014.

\section{BIOGRAPHIES}

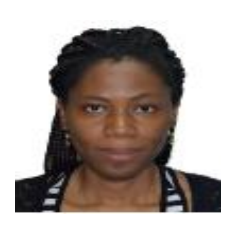

PhD candidate at Jiangsu University.

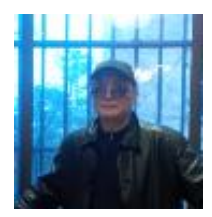

$\mathrm{PhD}$ Supervisor in Civil Engineering at Jiangsu University. 